\title{
The bioavailability of bromazepam, omeprazole and paracetamol given by nasogastric feeding tube
}

\author{
Gregory Podilsky • Markoulina Berger-Gryllaki • \\ Bernard Testa • Thierry Buclin • Michel Roulet • \\ Andre Pannatier
}

Received: 10 October 2008 / Accepted: 31 December 2008/Published online: 3 February 2009

(C) Springer-Verlag 2009

\begin{abstract}
Aims To characterize and compare the pharmacokinetic profiles of bromazepam, omeprazole and paracetamol when administered by the oral and nasogastric routes to the same healthy cohort of volunteers.

Methods In a prospective, monocentric, randomized crossover study, eight healthy volunteers received the three drugs by the oral (OR) and nasogastric routes (NT). Sequential plasma samples were analyzed by high-performance liquid chromatography-UV, pharmacokinetic parameters $\left(\mathrm{C}_{\max }\right.$, $\left.\mathrm{AUC}_{0-\infty}, \mathrm{t}_{1 / 2}, \mathrm{k}_{\mathrm{e}}, \mathrm{t}_{\max }\right)$ were compared statistically, and $\mathrm{C}_{\max }, \mathrm{AUC}_{0-\infty}$ and $\mathrm{t}_{\max }$ were analyzed for bioequivalence. Results A statistically significant difference was seen in the $\mathrm{AUC}_{0-\infty}$ of bromazepam, with nasogastric administration decreasing availability by about $25 \%: \mathrm{AUC}_{\mathrm{OR}}=2501 \mathrm{ng} \mathrm{mL}^{-1} \mathrm{~h}$; $\mathrm{AUC}_{\mathrm{NT}}=1855 \mathrm{ng} \mathrm{mL}^{-1} \mathrm{~h}(p<0.05)$; ratio (geometric mean) $=$ 0.74 [ $90 \%$ confidence interval (CI) $0.64-0.87]$. However, this does not appear to be clinically relevant given the usual
\end{abstract}

G. Podilsky $\cdot$ M. Berger-Gryllaki $\cdot$ B. Testa $\cdot$ A. Pannatier $(\bowtie)$ Department of Pharmacy, University Hospital Centre,

Rue du Bugnon 46,

1011 Lausanne, Switzerland

e-mail: Andre.Pannatier@chuv.ch

T. Buclin

Division of Clinical Pharmacology, University Hospital Lausanne, Lausanne, Switzerland

M. Roulet

Clinical Nutrition Unit, University Hospital Lausanne,

Lausanne, Switzerland

\section{A. Pannatier}

School of Pharmaceutical Sciences, EPGL, University of Geneva, University of Lausanne,

Geneva, Switzerland dosage range and the drug's half-life (approx. $30 \mathrm{~h}$ ). A large interindividual variability in omeprazole parameters prevented any statistical conclusion from being drawn in terms of both modes of administration despite their similar average profile: $\mathrm{AUC}_{\mathrm{OR}}=579 \mathrm{ng} \mathrm{mL}{ }^{-1} \mathrm{~h} ; \mathrm{AUC}_{\mathrm{NT}}=587 \mathrm{ng} \mathrm{mL}^{-1} \mathrm{~h}(p>0.05)$; ratio (geometric mean) $=1.01(90 \%$ CI0.64-1.61). An extended study with a larger number of subjects may possibly provide clearer answers. The narrow 90\% confidence limits of paracetamol indicate bioequivalence: $\mathrm{AUC}_{\mathrm{OR}}=37 \mu \mathrm{g} \mathrm{mL}^{-1} \mathrm{~h} ; \mathrm{AUC}_{\mathrm{NT}}=41 \mu \mathrm{g} \mathrm{mL} \mathrm{g}^{-1} \mathrm{~h}(p>0.05)$; ratio $($ geometric mean $)=1.12(90 \%$ CI0.98-1.28) .

Conclusion The results of this study show that the nasogastric route of administration does not appear to cause marked, clinically unsuitable alterations in the bioavailability of the tested drugs.

Keywords Bioavailability · Bromazepam

Nasogastric route - Omeprazole Oral route $\cdot$ Paracetamol · Pharmacokinetics

\section{Introduction}

Patient feeding by nasogastric tube has gained increased significance in recent years, and techniques have improved concurrently [1-3]. Thus, the number of patient-days for which nasogastric feeding was provided in our intensive care unit has grown from 5\% in 1986 to $30 \%$ in 1995 [4]. In $2000,3.6 \%$ of 1350 patients in our University Hospital ( 860 beds) were nourished by means of a nasogastric tube for an average period of 20 days.

In such patients, the oral route of drug administration has been quite naturally replaced by the nasogastric route. An unpublished survey carried out in our hospital showed that in $2001,72 \%$ of tube-fed patients in the departments of 
otolaryngology, surgery and medicine received their oral drugs by this route. Of the 29 patients observed, 15 (52\%) were fitted with a nasogastric tube, ten (34\%) with a percutaneous endoscopic gastrostomy and four (14\%) with a jejunostomy. The average number of drugs was 6.5 per patient (range 1-15). Analgesics represented 16\% of all drugs administered in this manner and antipsychotics $13 \%$. Most medicines were tablets (59\%), followed by effervescent tablets $(14 \%)$, oral drops $(12 \%)$ and sirups $(10 \%)$. As such, most medicines had to be crushed before being added to the feeding suspension. However, such an operation is not suitable for enterosoluble and slow-release tablets. Furthermore, the oral absorption profile and bioavailability of drugs could not be guaranteed because they remained untested; this is without taking into account possible physicochemical incompatibilities with polymeric material in the tubes.

Studies addressing this issue are scarce, with the best investigated drugs to date being theophylline, phenytoin and antibacterial quinolones. A number of in vitro and in vivo studies as well as case reports have led to contradictory conclusions for all three of these drugs [5-13]. A literature review published in 2000 [14] concluded that phenytoin administration by nasogastric tube led to decreased absorption and lower than expected plasma concentrations. However, the conclusions of this survey seem to ignore the results from four randomized controlled clinical trials which showed no decrease in absorption. The bioavailability of theophylline is known to be decreased in the presence of food. A case report found the same phenomenon upon administration by nasogastric tube [15]. However, two subsequent studies have failed to reproduce this finding and reported an unaffected bioavailability $[16,17]$. Antibacterial quinolones, such as ciprofloxacine and ofloxacine, are well absorbed orally, a fact suggesting a similar behaviour following administration by nasogastric tube. Yet a decreased absorption following administration by the latter route was demonstrated for ciprofloxacine and ofloxacine [18]. Another study also found significant losses for ciprofloxacine, ofloxacine and levofloxacine when these were mixed with an enteral feeding formulation [19], suggesting that the phenomenon was a characteristic of this whole class of drugs. In contrast, the bioavailability of gatifloxacine was found to remain unaffected when administered together with enteral food in injured patients [20], as was the absorption of moxifloxacine or trovafloxacine in healthy volunteers [21, 22]. An opposite result was later seen with gatifloxacine in healthy volunteers [23].

Our review of the literature thus brings to light contradictory results. This may be partly due to large differences between methodologies, but a salient characteristic in all of the above studies is that they did not use the same subjects to compare oral versus nasogastric drug administration. We have therefore designed a monocentric, prospective, crossover and randomized clinical study in healthy volunteers, with the aim of comparing the pharmacokinetic profile of drugs administered orally and by the nasogastric route - in the same subjects. Three drugs were selected for the study based on their frequent use and relevance in nasally fed patients, namely paracetamol, bromazepam and omeprazole.

\section{Materials and methods}

Subjects and study design

Eight volunteers, four females and four males, aged 2127 years, were included in the study. They underwent a screening visit to assess their eligibility for the trial. Each volunteer took part in two separate phases of the investigation, one for oral administration and the other for nasogastric administration. The sequence was randomized, and the two phases were separated by a 28 -day washout period to avoid intra-individual hormonal differences in the female subjects. The investigation took place in the Division of Clinical Pharmacology of our University Hospital under the constant supervision of at least one investigator. The protocol was approved by the Ethics Committee for Clinical Research of the Faculty of Biology and Medicine of the University of Lausanne.

The nasogastric feeding phase began at 0700 hours. A polyurethane tube (Freka, Fribourg, Switzerland; length $120 \mathrm{~cm}$, internal diameter $2.1 \mathrm{~mm}$, external diameter $2.8 \mathrm{~mm}$ ) was placed according to standard procedures. The subject was then fed continuously for $24 \mathrm{~h}\left(30 \mathrm{kcal} \mathrm{kg}^{-1}\right.$ day $^{-1}$ ) with an Isosource Energy suspension (1.5 $\mathrm{kcal} \mathrm{mL}^{-1}$; Novartis Pharma, Basel, Switzerland) using a Compat enteral feeding pump (Novartis). During the first day, the volunteers were allowed to consume $500 \mathrm{~mL}$ of water. On the following day, a first blood sample was collected from each subject (labelled as $\mathrm{t}_{0}$ ). One hour later, each subject was administered three drugs separately by the nasogastric route within a 5-min period in the following sequence: one tablet of Lexotanil $3 \mathrm{mg}$ (bromazepam; Roche Pharma, Reinach, Switzerland), one tablet of Antramups $20 \mathrm{mg}$ (omeprazole; AstraZeneca, Zug, Switzerland) and one effervescent tablet of Dafalgan $1 \mathrm{~g}$ (paracetamol; UPSA, Baar, Switzerland). The tablets were dissolved or suspended in a small volume of water, with the suspension or solution being instilled with a syringe into the nasogastric tube. The syringe was rinsed with $10 \mathrm{~mL}$ water between instillations. The Antramups tablet (Multiple Unit Pellet System) is a disintegrating formulation containing enteric-coated micropellets (diameter approx. $500 \mu \mathrm{m}$ ) of omeprazole. The resulting suspension was administered by nasogastric tube within approximately 
2 min under constant, gentle lateral shaking. The feeding tube was withdrawn $10 \mathrm{~h}$ after nasogastric drug administration, and the subjects received a standard meal. Blood samples $(10 \mathrm{~mL})$ were collected at 20 and $40 \mathrm{~min}$ and $1,1.5$, $2,3,4,6,8,12,24$ and $48 \mathrm{~h}$ after dosing. The venous catheter was rinsed with $3 \mathrm{~mL} \mathrm{NaCl} 0.9 \%$ after each blood collection.

On day 1 of the oral administration phase, the volunteers received standard meals at 0730,1200 and 1830 hours; no other food intake was allowed. Beverage intake was limited to $1.5 \mathrm{~L}$. The second day was the day of drug administration, which again involved placing a venous catheter and taking a first blood sample as reference $\left(\mathrm{t}_{0}\right)$ at 0700 hours. One hour later, the subject was orally administered one tablet of Lexotanil $3 \mathrm{mg}$, one tablet of Antramus $20 \mathrm{mg}$ and one tablet of Dafalgan effervescent $1 \mathrm{~g}$ together with $200 \mathrm{~mL}$ water. Blood samples were collected as above. During this day, the subjects remained supine and received three standard meals, as on the previous day.

\section{Treatment and analysis of plasma samples}

Within minutes of collection, each blood sample was placed in a CPDA tube and centrifuged at $3200 \mathrm{rpm}$ for $12 \mathrm{~min}$ at $4^{\circ} \mathrm{C}$. Plasma samples were then divided into $2-\mathrm{mL}$ portions, which were immediately frozen at $-20^{\circ} \mathrm{C}$, then at $-80^{\circ} \mathrm{C}$ for optimal preservation of omeprazole [24].

Determination of the dosage of paracetamol was carried out by high-performance liquid chromatography (HPLC) according to a published protocol, using 3-acetaminophenol as the internal standard [25]. The samples first underwent solid-phase extraction using Focus columns $(6$ and $50 \mathrm{~mL}$, respectively) from Varian (Palo Alto, CA). The columns were first conditioned with $2 \mathrm{~mL}$ of a 50:50 mixture of methanol and formic acid $2 \%$, then loaded with the plasma sample $(200 \mu \mathrm{L})$ and $100 \mu \mathrm{L}$ of internal standard $(10 \mu \mathrm{g})$

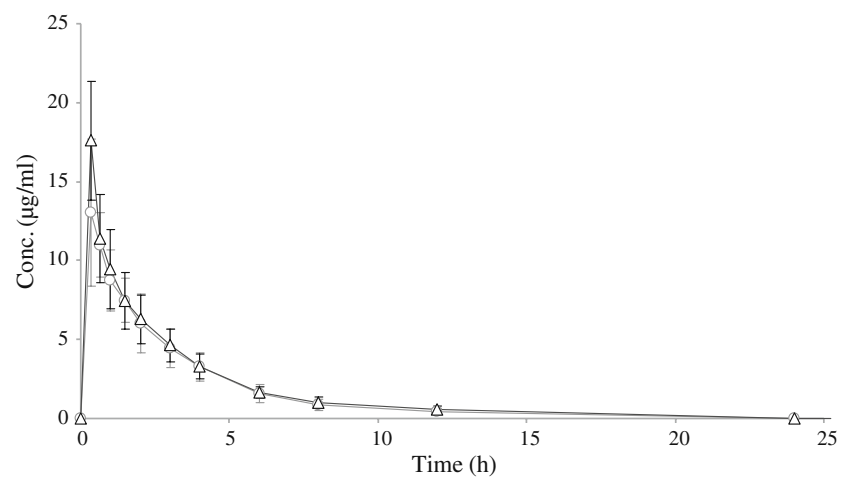

Fig. 1 Mean concentration curve [with standard deviation (SD) given by vertical bars] obtained after oral (open circles) or nasogastric (open triangles) administration of a single $1000 \mathrm{mg}$ dose of paracetamol effervescent

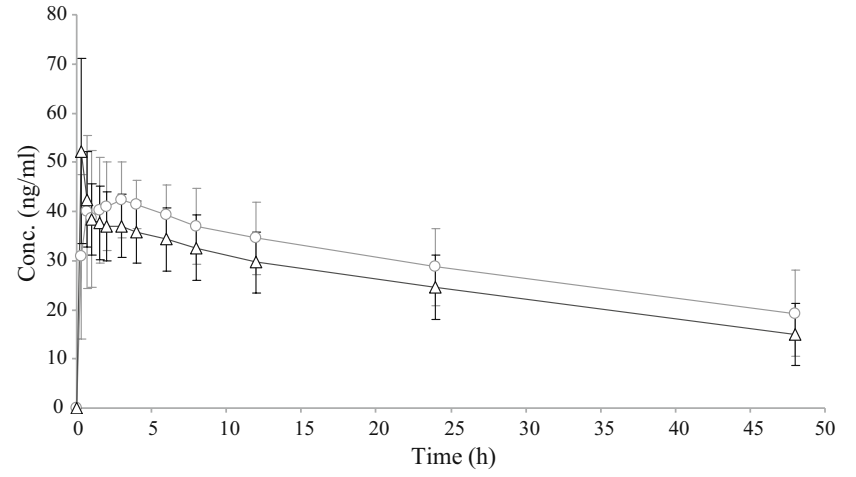

Fig. 2 Mean concentration curve (with SD given by vertical bars) obtained after oral (open circles) or nasogastric (open triangles) administration of a single $3 \mathrm{mg}$ dose of bromazepam

and finally washed with $1 \mathrm{~mL}$ methanol $5 \%$. The columns were then extracted with $1 \mathrm{~mL}$ methanol; the eluate was collected in polycarbonate tubes, evaporated under a nitrogen flux and dissolved into $200 \mu \mathrm{L}$ eluent.

The quantification of paracetamol was carried out by HPLC using a Varian instrument equipped with a Prostar 230 pump, a Prostar 410 automatic injector and a Prostar 310 UV detector. The column was a Lichrospher $60 \mathrm{Rp}$ Select B $(4.0 \times 250 \mathrm{~mm}$, internal diameter $5 \mu \mathrm{m})$ equipped with a LiChroCART 4-4 precolumn (Merck KgaA, Darmstadt, Germany). A gradient mode was used, starting with acetonitrile $2 \%$ ramped linearly to $50 \%$ in $15 \mathrm{~min}$, then to $55 \%$ in $5 \mathrm{~min}$ and returning to the initial percentage. The flow rate was $1.3 \mathrm{~mL} \mathrm{~min}^{-1}$ and the injection volume was $50 \mu \mathrm{L}$. Ultraviolet detection was at $245 \mathrm{~nm}$. The validation of the method [26] gave a limit of detection of $0.137 \mathrm{ng}$ $\mathrm{mL}^{-1}$, while the lower and upper limits of quantification were 0.2 and $40 \mu \mathrm{g} \mathrm{mL}{ }^{-1}$, respectively. This range was considered to be satisfactory given the expected concentrations \{highest plasma concentration following a single dose $\left(\mathrm{C}_{\max }\right) 6-22 \mu \mathrm{g} \mathrm{mL} \mathrm{m}^{-1}$ following a single $1000 \mathrm{mg}$ dose of paracetamol $[27-30]\}$. The lower limit of quanti-

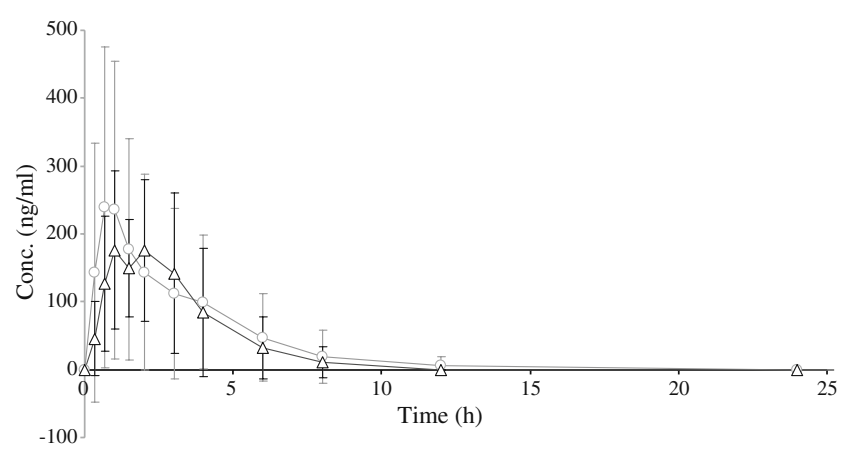

Fig. 3 Mean concentration curve (with SD given by vertical bars) obtained after oral (open circles) or nasogastric (open triangles) administration of a single $20 \mathrm{mg}$ dose of omeprazole 

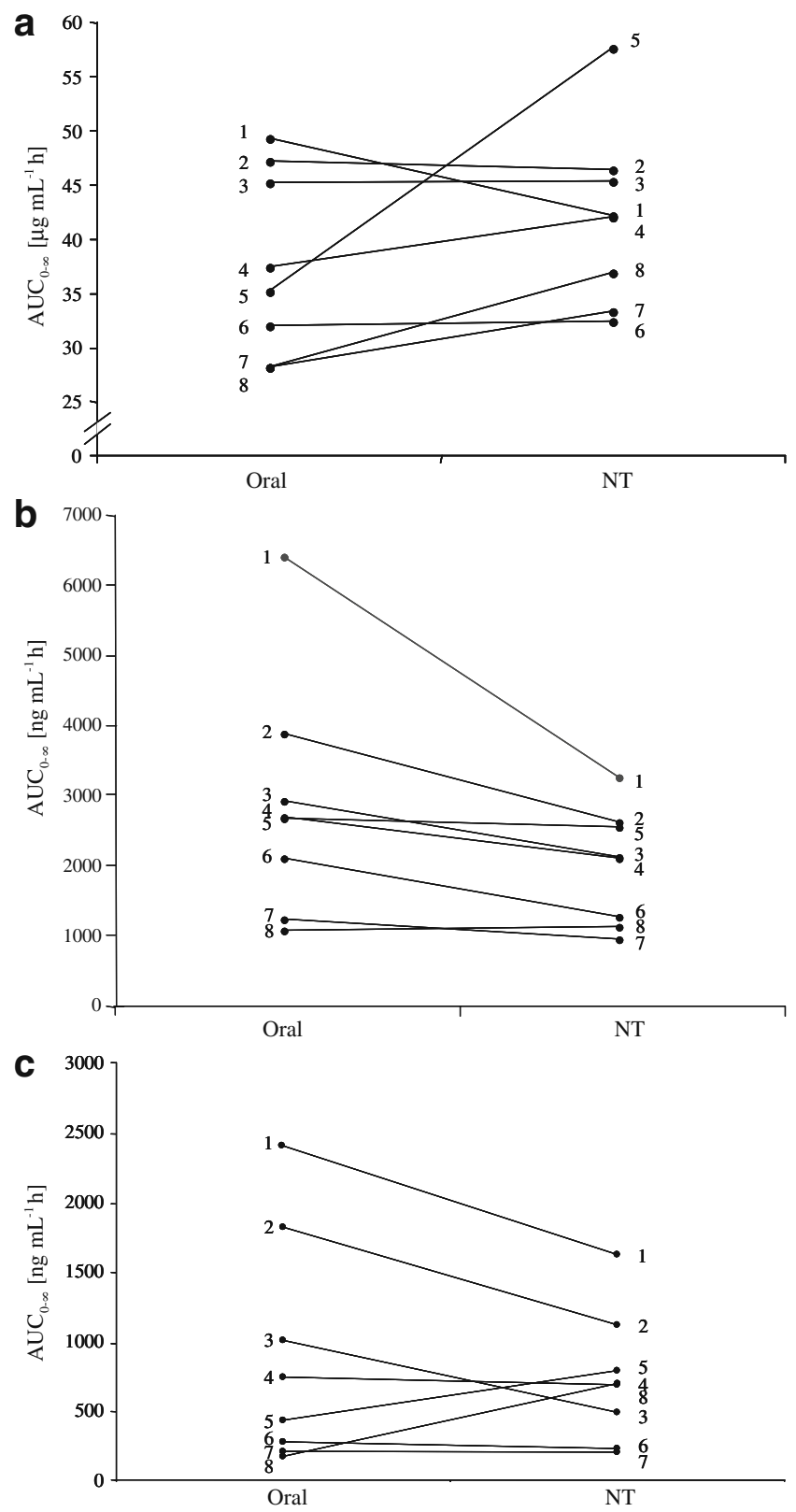

Fig. 4 Intra- and interindividual variations of the area under the plasma time-concentration curve $\left(\mathrm{AUC}_{0-\infty}\right)$ for the eight subjects (1-8): a following a single dose of $1000 \mathrm{mg}$ of effervescent paracetamol orally or by nasogastric tube $(N T)$, b following a single dose of $3 \mathrm{mg}$ of bromazepam orally and by NT, c following a single dose of $20 \mathrm{mg}$ of omeprazole orally and by NT

fication $\left(0.2 \mu \mathrm{g} \mathrm{mL}^{-1}\right)$ was also to be considered satisfactory since such low concentrations are found only at the end of the terminal elimination phase and have only a negligible influence on pharmacokinetic parameters, such as $\lambda_{z}, t_{1 / 2}$ and area under the plasma time concentration curve (AUC). The precision [coefficient of variation $(\mathrm{CV} \%)]$ in inter-and intra-assays was less than $6.3 \%$ at all concentration levels. The accuracy ranged from 95.3 to $101.1 \%$ of the mean values.
Bromazepam and omeprazole concentrations were measured simultaneously using oxazepam as the internal standard, as previously described [31].

The validation of the method [26] gave a limit of detection of $4.55 \mathrm{ng} \mathrm{mL}^{-1}$ for bromazepam and $2.01 \mathrm{ng} \mathrm{mL}^{-1}$ for omeprazole. The lower and upper limits of quantification were 5 and $100 \mathrm{ng} \mathrm{mL}^{-1}$ for bromazepam and 20 and $2000 \mathrm{ng} \mathrm{mL}^{-1}$ for omeprazole, respectively. The precision $(\mathrm{CV} \%)$ in inter- and intra-assays was less than $8.8 \%$ (lowest level) for bromazepam and $14.4 \%$ (lowest level) for omeprazole at all concentration levels. The accuracy ranged from 96.3 to $99.3 \%$ for bromazepam and from 88.3 to $107.9 \%$ for omeprazole.

Pharmacokinetic parameters and statistical analysis

The pharmacokinetic analysis was based on a "noncompartmental" approach. Two pharmacokinetic parameters were derived directly from the concentration-time curves, namely $\mathrm{C}_{\max }$ and $\mathrm{t}_{\max }$ (time to reach $\mathrm{C}_{\max }$ ). The other parameters were calculated using appropriate equations in the Excel 2004 V.11.3 program from Microsoft (Richmond, VA): $\lambda_{z}$ (apparent constant of terminal elimination), $t_{1 / 2}$ (elimination half-life), $\mathrm{AUC}_{0-\infty}$ (area under the curve from zero to $\mathrm{t}$ estimated by the trapezoidal method and log-trapezoidal method for post-absorption phase, and from $\mathrm{t}$ to infinity by extrapolation), and $\mathrm{CL} / \mathrm{F}$ (apparent clearance where $\mathrm{CL}=$ clearance and $\mathrm{F}=$ bioavailability).

The pharmacokinetic parameters characterizing both modes of administration were compared statistically and submitted to a bioequivalence analysis. A log-normal distribution of values was assumed [32]. Each set of data was analysed with a quantile-quantile plot (QQ Plot) [33, 34]. When no distribution was apparent, a curve of cumulated distribution was plotted to complete the analysis [35]. The log-normality of the various variables could be confirmed based on the graphical evaluation; a statistical analysis was thus carried out with a parametric test ( $t$-paired test) using the logarithm transformation of the data. The only exception was the discrete variable $t_{\max }$, which was analyzed by the non-parametric Wilcoxon's signed-ranks test [36]. In both cases, the threshold of significance was taken to be $p=0.05$.

A bioequivalence analysis was carried out to assess the similitude of exposure between the two modes of administration. The three parameters compared were $\mathrm{AUC}_{0-\infty}$, $\mathrm{C}_{\max }$ and $\mathrm{t}_{\max }$. As recommended by the Federal Drug Administration and the European Agency for the Evaluation of Medicinal Products [37, 38], the geometric mean, the $\mathrm{CV}$ and the minimal and maximal values were calculated. Bioequivalence was then assessed by analyzing the $90 \%$ confidence limits $(90 \% \mathrm{CI})$ around the geometric mean of the primary parameters $\left(\mathrm{C}_{\max }\right)$ and $\left.\mathrm{AUC}_{0-\infty}\right)$ 
Table 1 Statistic analysis of pharmacokinetic parameters obtained after oral or nasogastric (NA) administration of a single dose of $1000 \mathrm{mg}$ paracetamol

\begin{tabular}{|c|c|c|c|c|c|}
\hline Parameters $^{\mathrm{a}}$ & Mode of administration & Geometric mean & $\begin{array}{l}\text { Coefficient of variation } \\
(\%)\end{array}$ & Ratio geometric mean & $90 \%$ Confidence interval \\
\hline \multirow{2}{*}{$\mathrm{C}_{\max }\left(\mu \mathrm{g} \mathrm{mL} L^{-1}\right)$} & Oral & 14.0 & 22.6 & & \\
\hline & NT & 17.7 & 20.1 & 1.26 & $1.04-1.53$ \\
\hline \multirow[t]{2}{*}{$\mathrm{t}_{\max }(\mathrm{h})$} & Oral & 0.41 & 36.8 & & \\
\hline & NT & 0.34 & 35.4 & & \\
\hline \multirow[t]{2}{*}{$\lambda_{\mathrm{z}}\left(\mathrm{h}^{-1}\right)$} & Oral & 0.28 & $13.6^{*}$ & & \\
\hline & NT & 0.26 & 14.9 & & \\
\hline \multirow[t]{2}{*}{$t_{1 / 2}(h)$} & Oral & 2.45 & $13.6^{*}$ & & \\
\hline & NT & 2.68 & 14.9 & & \\
\hline \multirow[t]{2}{*}{$\mathrm{AUC}_{0-\infty}\left(\mu \mathrm{g} \mathrm{mL}{ }^{-1} \mathrm{~h}\right)$} & Oral & 37.0 & 25.4 & & \\
\hline & NT & 41.3 & 20.9 & 1.12 & $0.98-1.28$ \\
\hline \multirow[t]{2}{*}{$\mathrm{CL} / \mathrm{F}\left(\mathrm{mL} \min ^{-1}\right)$} & Oral & 451 & 25.4 & & \\
\hline & NT & 403 & 20.9 & & \\
\hline
\end{tabular}

$* p<0.05$

${ }^{a} C_{\max }$, Highest plasma concentration following a single dose; $t_{\max }$, time to reach $\mathrm{C}_{\max } ; \mathrm{t}_{1 / 2}$, elimination half-life; $\lambda_{\mathrm{z}}$, apparent constant of terminal elimination; $\mathrm{AUC}_{0-\infty}$, area under the curve from zero to infinity; $\mathrm{CL} / \mathrm{F}$, apparent clearance with $\mathrm{CL}$ (clearance) and $\mathrm{F}$ (bioavailability)

assuming their log-normal distribution. However, the major criteria was $\mathrm{AUC}_{0-\infty}$ since the time intervals of sampling did not allow an accurate determination of $\mathrm{C}_{\max }$ and $\mathrm{t}_{\max }$. The statistical tool $\mathrm{R}$ ver.1.16 of the $\mathrm{R}$ Foundation for Statistics (Faculty of Economics, Vienna, Austria) was used for all analyses [39].

\section{Results}

The mean concentration curves (with their standard deviation, SD) obtained after oral or nasogastric administration are shown for paracetamol (1 $\mathrm{g}$ dose), bromazepam (3 mg dose) and omeprazole (20 mg dose) in Figs. 1, 2 and 3 , respectively.

\section{Pharmacokinetic parameters of paracetamol}

The pharmacokinetic parameters of paracetamol are shown in Table 1 together with their geometric mean (GeoM) and $\mathrm{CV}$. The only marginally significant difference between the oral and nasogastric modes of administration is seen in the parameters of the elimination phase $\left(\lambda_{z}\right.$ and $\left.t_{1 / 2}\right)$. The $C_{\max }$ values do not satisfy the bioequivalence criterion and are at the limit of statistical significance $(p=0.06)$, whereas the $\mathrm{t}_{\max }$ values are identical for both modes of administration. For the $\mathrm{AUC}_{0-\infty}$, the $90 \% \mathrm{CI}$ extends slightly beyond the recognized criteria of bioequivalence $(0.80-1.25)$. Figure $4 \mathrm{a}$ illustrates the intra- and interindividual variations of $\mathrm{AUC}_{0-\infty}$ for the eight subjects. No clear-cut influence of the mode of administration can be found, as confirmed by CV of 25 and $21 \%$ for oral and nasogastric administration, respectively.

\section{Pharmacokinetic parameters of bromazepam}

The pharmacokinetic parameters of bromazepam are shown in Table 2. The parameters of the elimination phase $\left(\lambda_{z}\right.$ and $t_{1 / 2}$ ) do not reveal any meaningful difference between both modes of administration. The $\mathrm{C}_{\max }$ results suggest a higher value $(p<0.05)$ after nasogastric administration. Bioequivalence is therefore absent based on CI limits of $0.8-1.25$, but is satisfied within the $0.75-1.33$ limits. The $90 \%$ CI values show that the $\mathrm{AUC}_{0 \text {-last }}$ parameter does not fulfil the criterion of bioequivalence.

Figure $4 \mathrm{~b}$ illustrates the intra- and interindividual variations of $\mathrm{AUC}_{0-\infty}$ for the eight subjects. An average decrease of $26 \%$ was found for nasogastric administration. Also, the inter-subject variation is larger after oral administration (CV 78\%).

\section{Pharmacokinetic parameters of omeprazole}

The pharmacokinetic parameters of omeprazole are reported in Table 3. With the exception of $\lambda_{z}$ and $t_{1 / 2}$, no significant difference was seen between these modes. The $90 \% \mathrm{CI}$ of $\mathrm{C}_{\max }$ and $\mathrm{AUC}_{0-\infty}$ do not satisfy the criteria of bioequivalence. The mean of the ratios $(1.01, p=0.95)$ does not indicate that the exposure to the drug is different after both modes of administration. The CV for oral $(172 \%)$ and nasogastric (107\%) administration point to an important interindividual variation, as confirmed by the $90 \% \mathrm{CI}$ in the broad range of $0.64-1.61$. This variability is also reflected in the $90 \% \mathrm{CI}$ of $\mathrm{C}_{\max }(0.71-2.16)$ and in the $\mathrm{AUC}_{0-\infty}$ values (Fig. 4c). Interestingly, in six of the eight subjects nasogastric administration led to slightly lower $\mathrm{AUC}_{0-\infty}$ values. 
Table 2 Statistic analysis of pharmacokinetic parameters obtained after oral or nasogastric administration of a single dose of 3 mg bromazepam

\begin{tabular}{|c|c|c|c|c|c|}
\hline Parameters & Mode of administration & Geometric mean & Coefficient of variation & Ratio geometric mean & $90 \%$ Confidence interval \\
\hline \multirow[t]{2}{*}{$\mathrm{C}_{\max }\left(\mathrm{ng} \mathrm{mL}^{-1}\right)$} & Oral & 46.0 & $19.7 *$ & & \\
\hline & NT & 55.1 & 25.3 & 1.20 & $1.10-1.30$ \\
\hline \multirow[t]{2}{*}{$\mathrm{t}_{\max }(\mathrm{h})$} & Oral & 1.53 & $152.0^{*}$ & & \\
\hline & NT & 0.53 & 160.3 & & \\
\hline \multirow[t]{2}{*}{$\lambda_{\mathrm{z}}\left(\mathrm{h}^{-1}\right)$} & Oral & 0.02 & 71.9 & & \\
\hline & NT & 0.02 & 40.3 & & \\
\hline \multirow[t]{2}{*}{$t_{1 / 2}(h)$} & Oral & 39.7 & 71.9 & & \\
\hline & NT & 33.3 & 40.3 & & \\
\hline \multirow[t]{2}{*}{$\mathrm{AUC}_{0-\infty}\left(\mathrm{ng} \mathrm{mL}^{-1} \mathrm{~h}\right)$} & Oral & 2501 & $78.0^{*}$ & & \\
\hline & NT & 1855 & 56.0 & 0.74 & $(0.64-0.87)$ \\
\hline \multirow[t]{2}{*}{$\mathrm{CL} / \mathrm{F}\left(\mathrm{mL} \min ^{-1}\right)$} & Oral & 20.0 & $78.0^{*}$ & & \\
\hline & NT & 27.0 & 56.0 & & \\
\hline
\end{tabular}

$* p<0.05$

\section{Discussion}

Before discussing individual results, it is important to outline the risk of bias due to dose effects. Even with a strictly defined protocol, it was impossible to guarantee that all subjects received $100 \%$ of the nominal dose. As shown in a preliminary in vitro study, no physicochemical interaction was seen between the three drugs. However, a loss of omeprazole of up to $20 \%$ was due to residual pellets after dispersion, dissolution and rinsing. Nevertheless, the pharmacokinetic analysis was based on the intended nominal dose, as is customary in clinical trials with nasogastric tubes.

Prior to the clinical phase, in vitro simulations with nasogastric tubes were carried out for the three drugs in the presence and absence of the feeding suspension. No loss of drug was seen with bromazepam and paracetamol. The problem was more difficult for omeprazole, and various methods of administration were examined. Because our hospital uses Freka 8Fr tubes, the 30-s instillation technique described by Sostek et al. [40] using 16Fr tubes could not be applied. Omeprazole was therefore instilled over a 2-min interval. As already described in the literature [41], we also observed a loss of drug up to $20 \%$, presumably caused by the loss of residual pellets even with careful rinsing.

Another issue that requires attention is the small number of subjects, which limits the statistical impact of the study. This small number is compensated for by the fact that each subject was his/her control. Furthermore, in the absence of any preliminary indications of the magnitude of effects to be expected, no formal power calculation could be performed. Our investigation was mainly a pilot study aimed at determining whether the administration of the test drugs through a nasogastric tube induced any alteration in the bioavailability of these drugs that was sufficient to warrant further study.
Pharmacokinetic parameters of paracetamol

The AUC values extend slightly beyond the rigorous bioequivalence criterion, but this does not exclude a bioequivalence between oral and nasogastric administration. Indeed, in rare cases, a wider acceptance range may be acceptable, especially if the activity and safety profiles are well established [36], as is the case for paracetamol. Under such conditions, a wider bioequivalence criterion (e.g. $0.75-1.33$ or even $0.70-1.42$ ) could appear to be justified. Our results confirm the interest of an effervescent formulation for drug dissolution prior to nasogastric administration. They are also in line with those of many clinical investigations that show the lack of an effect of food or formulation on paracetamol bioavailability. Paracetamol has also been used as a marker of gastric emptying following

Table 3 Statistic analysis of pharmacokinetic parameters obtained after oral or nasogastric administration of a single dose of $20 \mathrm{mg}$ omeprazole

\begin{tabular}{|c|c|c|c|c|c|}
\hline Parameters & $\begin{array}{l}\text { Mode of } \\
\text { administration }\end{array}$ & $\begin{array}{l}\text { Geometric } \\
\text { mean }\end{array}$ & $\begin{array}{l}\text { Coefficient of } \\
\text { variation (\%) }\end{array}$ & $\begin{array}{l}\text { Ratio } \\
\text { GeoM }\end{array}$ & $\begin{array}{l}90 \% \\
\mathrm{CI}\end{array}$ \\
\hline \multirow{2}{*}{$\begin{array}{l}\mathrm{C}_{\max } \\
\left(\mathrm{ng} \mathrm{mL} L^{-1}\right)\end{array}$} & Oral & 189 & 170.2 & & \\
\hline & NT & 234 & 57.2 & 1.24 & $\begin{array}{l}0.71- \\
2.16\end{array}$ \\
\hline \multirow[t]{2}{*}{$\mathrm{t}_{\max }(\mathrm{h})$} & Oral & 1.33 & 116.3 & & \\
\hline & NT & 1.23 & 74.0 & & \\
\hline \multirow[t]{2}{*}{$\lambda_{z}\left(h^{-1}\right)$} & Oral & 0.29 & $172.7 *$ & & \\
\hline & NT & 0.60 & 61.9 & & \\
\hline \multirow[t]{2}{*}{$t_{1 / 2}(h)$} & Oral & 2.42 & $172.7^{*}$ & & \\
\hline & NT & 1.16 & 61.9 & & \\
\hline \multirow{2}{*}{$\begin{array}{l}\mathrm{AUC}_{0-\infty} \\
\left(\mathrm{ng} \mathrm{mL}^{-1} \mathrm{~h}\right)\end{array}$} & Oral & 579 & 172.1 & & \\
\hline & NT & 587 & 107.5 & 1.01 & $\begin{array}{l}0.64- \\
1.61\end{array}$ \\
\hline \multirow{2}{*}{$\begin{array}{l}\mathrm{CL} / \mathrm{F} \\
\left(\mathrm{mL} \min ^{-1}\right)\end{array}$} & Oral & 576.1 & 172.1 & & \\
\hline & NT & 568 & 107.5 & & \\
\hline
\end{tabular}

${ }^{*} p<0.05$ 
nasogastric feeding. Again, other published results are in line with those reported here.

\section{Pharmacokinetic parameters of bromazepam}

Our results indicate that the nasogastric administration of bromazepam produces a decrease of about $25 \%$ in its $\mathrm{AUC}_{0-\infty}$ compared to oral administration. Given the fact that $\mathrm{C}_{\max }$ increased while AUC decreased, we postulate that this decreased AUC is due to an increase in apparent clearance $(\mathrm{CL} / \mathrm{F})$ following nasogastric administration $(p=$ 0.008). Even if this difference is pharmacokinetically real, its clinical impact should be modest or negligible given the single-dose administration and $\mathrm{C}_{\max }$ variations, which remained within the limits of no real therapeutic significance. An average value of $2.5 \mathrm{mg} \mathrm{mL}^{-1} \mathrm{~h}(\mathrm{CV}=78 \%)$ after an oral administration of $3 \mathrm{mg}$, as found here, is larger than that found in other studies, but is close to our finding after nasogastric administration $\left(1.85 \mathrm{mg} \mathrm{mL}^{-1} \mathrm{~h}, \mathrm{CV}=56 \%\right)$. The half-lives observed after both modes of administration were comparable, whereas the apparent clearance was increased after nasogastric administration. By combining these two observations and knowing that for extravascular administration the apparent clearance includes absorption chances, the latter appears to be the most likely cause for the difference in AUC.

\section{Pharmacokinetic parameters of omeprazole}

The plasma concentration curves clearly illustrate large interindividual variations, as reflected in the $\mathrm{CV}$ of the pharmacokinetic parameters and, in particular, of $\mathrm{C}_{\max }$ and $\mathrm{AUC}_{0-\infty}$. A potential cause for this behaviour may be the oxidative metabolism of omeprazole as catalysed by cytochromes P450 2C19 and 3A4. CYP2C19 is known to show polymorphism (3-5\% of poor metabolizers in a Caucasian population). However, it is difficult to evoke such a scenario in a small population of eight subjects. Also, it has repeatedly been shown that intersubject variability in omeprazole disposition depends on the dose and duration of administration and is believed to be due to the pharmacodynamic effect of the drug, namely a major decrease in gastric acidity, which decreases its breakdown. The loss of about $20 \%$ during administration could also contribute to the intra- and interindividual variability observed in omeprazole pharmacokinetics.

\section{Conclusion}

Despite the preliminary character of the study and the small number of subjects involved, taken globally, our results tend to demonstrate that the nasogastric route represents a viable mode of administration. Indeed, none of the three drugs examined showed a systematic and damaging loss in bioequivalence compared to the oral route. Furthermore, the nasogastric route seemed to show a smaller interindividual variation than the oral route. The clearest case was that of paracetamol, where no statistically significant difference was found. The AUC of bromazepam showed a fair intersubject variability, but the clinical impact should be modest or negligible given the limited range of $\mathrm{C}_{\max }$ variations. A large intersubject variability was seen for omeprazole, although no systematic difference in absorption could be evidenced. An extended study with a larger number of subjects may perhaps bring clearer answers.

In summary, our study was unable to demonstrate any clinically significant difference between the oral and nasogastric routes of administration of paracetamol, bromazepam and omeprazole in healthy volunteers. True bioequivalence according to standard criteria, however, remains difficult to establish on a limited number of subjects. In addition, it is not possible to extrapolate these conclusions to other classes of drugs, which deserve separate investigations. Comparative investigations may also prove useful to evaluate the impact on drug absorption of other enteric devices, such as tubes for jejunostomy or percutaneous endoscopic gastroscopy. Because such devices are invasive, their evaluation in healthy volunteers is not ethically justifiable and will have to be carried out in groups of patients. Only by applying this approach will it be possible to increase our understanding of how gastric tubes affect medication.

Acknowledgements The authors express their gratitude to Ms. Monique Appenzeller for her help during the trials, the nutrition nurse Ms. Isabelle Bordier, the technicians in the bioanalytical laboratory and the volunteers in this trial.

\section{References}

1. Randall HT (1984) Sixth annual Jonathan E. Rhoads lecture. Enteral nutrition: tube feeding in acute and chronic illness. J Parenter Enteral Nutr 8:113-136

2. Hébuterne X (1998) Technique de la nutrition entérale: matériel, solutions, modalités d'administration. Traité de nutrition artificielle de l'adulte. Société Française de Nutrition Clinique et Métabolisme, Paris, pp 445-463

3. Lochs H, Dejong C, Hammarqvist F et al (2006) ESPEN guidelines on enteral nutrition. Gastroenterol Clin Nutr 25:260-274

4. Berger MM, Chiolero R, Pannatier A et al (1997) A 10-year survey of nutritional support in a surgical ICU: 1986-1995. Nutrition 13:870-877

5. Bauer LA (1982) Interference of oral phenytoin absorption by continuous nasogastric feedings. Neurology 32:570-572

6. Holtz L, Milton J, Sturek JK (1987) Compatibility of medications with enteral feedings. J Parenter Enteral Nutr 11:183-186

7. Worden JP Jr, Wood CA Jr, Workman CH (1984) Phenytoin and nasogastric feedings. Neurology 34:132 
8. Saklad JJ, Graves RH, Sharp WP (1986) Interaction of oral phenytoin with enteral feedings. J Parenter Enteral Nutr 10:322323

9. Weinryb J, Cogen R (1989) Interaction of nasogastric phenytoin and enteral feeding solution. J Am Geriatr Soc 37:195-196

10. Hooks MA, Longe RL, Taylor AT et al (1986) Recovery of phenytoin from an enteral nutrient formula. Am J Hosp Pharm 43:685-688

11. Longe RL, Smith OB (1988) Phenytoin interaction with an oral feeding results in loss of seizure control. J Am Geriatr Soc 36:542-544

12. Rodman DP, Stevenson TL, Ray TR (1995) Phenytoin malabsorption after jejunostomy tube delivery. Pharmacotherapy 15:801-805

13. Hennessy DD (2003) Recovery of phenytoin from feeding formulas and protein mixtures. Am J Health Syst Pharm 60:1850-1852

14. Au Yeung SC, Ensom MH (2000) Phenytoin and enteral feedings: does evidence support an interaction? Ann Pharmacother 34:896905

15. Gal P, Layson R (1986) Interference with oral theophylline absorption by continuous nasogastric feedings. Ther Drug Monit 8:421-423

16. Bhargava VO, Schaaf LJ, Berlinger WG et al (1989) Effect of an enteral nutrient formula on sustained-release theophylline absorption. Ther Drug Monit 11:515-519

17. Plezia PM, Thornley SM, Kramer TH et al (1990) The influence of enteral feedings on sustained-release theophylline absorption. Pharmacotherapy 10:356-361

18. Mueller BA, Brierton DG, Abel SR et al (1994) Effect of enteral feeding with ensure on oral bioavailabilities of ofloxacin and ciprofloxacin. Antimicrob Agents Chemother 38:2101-2105

19. Wright DH, Pietz SL, Konstantinides FN et al (2000) Decreased in vitro fluoroquinolone concentrations after admixture with an enteral feeding formulation. J Parenter Enteral Nutr 24:42-48

20. Kanji S, McKinnon PS, Barletta JF et al (2003) Bioavailability of gatifloxacin by gastric tube administration with and without concomitant enteral feeding in critically ill patients. Crit Care Med 31:1347-1352

21. Burkhardt O, Stass H, Thuss U et al (2005) Effects of enteral feeding on the oral bioavailability of moxifloxacin in healthy volunteers. Clin Pharmacokinet 44:969-976

22. Vincent J, Teng R, Pelletier SM et al (1998) The bioavailability of nasogastric versus tablet-form oral trovafloxacin in healthy subjects. Am J Surg 176:23S-26S

23. Kays MB, Overholser BR, Lagvankar S et al (2005) Effect of ensure on the oral bioavailability of gatifloxacin in healthy volunteers. Pharmacotherapy 25:1530-1535

24. Garcia-Encina G, Farran R, Puig S et al (1999) Validation of an automated liquid chromatographic method for omeprazole in human plasma using on-line solid-phase extraction. J Pharm Biomed Anal 21:371-382

25. Berger MM, Berger-Gryllaki M, Wiesel PH (2000) Intestinal absorption in patients after cardiac surgery. Crit Care Med 28:2217-2223

26. Commission de la Société Française des Sciences et Techniques Pharmaceutiques (2003) Validation des procédures analytiques quantitatives. Harmonisation des démarches. STP Pharma Pratiques 13:101-138

27. Blase E, Taylor K, Gao HY et al (2005) Pharmacokinetics of an oral drug (acetaminophen) administered at various times in relation to subcutaneous injection of exenatide (exendin-4) in healthy subjects. J Clin Pharmacol 45:570-577

28. Stillings M, Havlik I, Chetty M et al (2000) Comparison of the pharmacokinetic profiles of soluble aspirin and solid paracetamol tablets in fed and fasted volunteers. Curr Med Res Opin 16:115-124

29. Stangier J, Su CA, Fraunhofer A et al (2000) Pharmacokinetics of acetaminophen and ibuprofen when coadministered with telmisartan in healthy volunteers. J Clin Pharmacol 40:1338-1346

30. Sevilla-Tirado FJ, Gonzalez-Vallejo EB, Leary AC et al (2003) Bioavailability of two new formulations of paracetamol, compared with three marketed formulations, in healthy volunteers. Methods Find Exp Clin Pharmacol 25:531-535

31. Podilsky G, Berger-Gryllaki M, Testa B et al (2008) Development and validation of an HPLC method for the simultaneous monitoring of bromazepam and omeprazole. J Liq Chrom Rel Technol 31:878-890

32. Lacey LF, Keene ON, Pritchard JF et al (1997) Common noncompartmental pharmacokinetic variables: are they normally or log-normally distributed? J Biopharm Stat 7:171-178

33. Henderson AR (2006) Testing experimental data for univariate normality. Clin Chim Acta 366:112-129

34. Weisstein EW (2006) Quantile-quantile plot. In: MathWorld. Wolfram Web Resource. Wolfram Research, Champaign, IL. Available at: http://mathworld.wolfram.com/Quantile-QuantilePlot. html. Accessed 10 Nov 2006

35. Weisstein EW (2006) Distribution Function. In: MathWorld. Wolfram Web Resource. Wolfram Research, Champaign, IL. Available at: http://mathworld.wolfram.com/DistributionFunction. html. Accessed 20 Oct 2006

36. Huguier M, Flahault A (2000) Biostatistiques au Quotidien. Elsevier, Paris

37. European Agency for the Evaluation of Medicinal Products (EMEA) Committee for Proprietary Medicinal Products (2001) Note for Guidance on the Investigation of Bioavailability and Bioequivalence. In: Scientific guidelines for human medical products. Available at: http://www.emea.europa.eu/pdfs/human/ ewp/140198en.pdf. Accessed 10 Feb 2008

38. U.S. Food and Drug Administration (FDA). Center for Drug Evaluation and Research (CDER) (2001) Statistical approaches to establishing bioequivalence. In: Guidance for industry. FDA, Washington D.C. Available at: http://www.accessdata.fda.gov/ scripts/cdrh/cfdocs/cfcfr/CFRSearch.cfm?CFRPart=320. Accessed 17 Feb 2008

39. R Development Core Team (2005) R: a language and environment for statistical computing. R Foundation for Statistical Computing, Vienna. Available at: http://www.R-project.org. Accessed Mar 2006

40. Sostek MB, Chen Y, Skammer W et al (2003) Esomeprazole administered through a nasogastric tube provides bioavailability similar to oral dosing. Aliment Pharmacol Ther 18:581-586

41. Dunn A, White CM, Reddy P (1999) Delivery of omeprazole and lansoprazole granules through a nasogastric tube in vitro. Am J Health Syst Pharm 56:2327-2330 